\title{
Follicular waves and circulating gonadotrophins in 8-month-old prepubertal heifers
}

\author{
G. P. Adams ${ }^{1}$, A. C. O. Evans ${ }^{2}$ and N. C. Rawlings ${ }^{2}$ \\ Departments of ${ }^{1}$ Veterinary Anatomy and ${ }^{2}$ Physiological Sciences, Western College of \\ Veterinary Medicine, University of Saskatchewan, Saskatoon, Saskatchewan, Canada S7N oWo
}

\begin{abstract}
Eleven age-matched ( \pm 4 days) Hereford heifers were examined by transrectal ultrasonography daily for 18 days beginning 20 weeks ( 5 months) before puberty (first ovulation) to determine the suitability of the transrectal ultrasound technique for imaging the ovaries of prepubertal heifers and to test the hypothesis that ovarian follicular development occurs in waves in prepubertal heifers. Satisfactory ovarian images were obtained during preliminary ultrasound examinations conducted 4 weeks before the observational period (that is 32 weeks of age), during which a semirigid probe extension was used to allow external manipulation of the intrarectally placed ultrasound transducer. Daily examinations commencing at 36 weeks of age were accomplished by intrarectal placement of the operator's hand and transducer, without complication, in all 11 heifers throughout the observational period. Periodic increases in the number of follicles detected (day effect, $P<0.02$ ) were inversely related to the diameter of the largest follicle $(r=-0.3, P<0.03)$. Portions of three anovulatory follicular waves were detected in all heifers during the observational period (first and third waves in part and second wave in whole). Individual follicles destined to assume a dominant or subordinate position in a wave were retrospectively identified and monitored beginning at a diameter of $4-5 \mathrm{~mm}$. The interval between the emergence of dominant follicles of successive waves (interwave interval) was $8.0 \pm 0.4$ days and the interval between successive maxima in the number of follicles per heifer per day was $8.1 \pm 0.5$ days. The growing phase of the dominant follicles best fit a quadratic curve. The growing phase of the largest subordinate follicles, and the static and regressing phases of dominant and subordinate follicles best fit simple linear expressions. Periodic surges in serum concentrations of FSH (day effect, $P<0.0001$ ), but not of LH (day effect, not significant), were associated with follicular wave dynamics. FSH surges (increase and decrease, respectively, best fit quadratic curves) spanned a mean of 3 days and reached maximum values $0.9 \pm 0.3$ days before emergence of the wave. Results supported the hypothesis that follicular development occurs in waves in prepubertal heifers. Mechanisms controlling the well-ordered phenomena of wave emergence, follicle selection and follicle regression, similar to those of sexually mature heifers, were present in 36-week-old prepubertal heifers.
\end{abstract}

\section{Introduction}

Ovarian follicular dynamics and associated changes in circulating gonadotrophins in postpubertal cattle have been characterized (Adams et al., 1992a), but little has been reported in this regard in prepubertal heifers. Changes in numbers of follicles have been examined in slaughtered cows of various age groups ranging from birth to 20 years $(n=5-16$ per group; Erickson, 1966), and in heifers slaughtered at intervals from birth to 12 months of age ( $n=5$ per month; Desjardins and Hafs, 1969). No antral follicles were visible macroscopically at birth, but their numbers appeared to increase to a maximum at 4-6

Received 19 January 1993. months, decrease to 8 months, and remain constant thereafter until senescent decline after 10-14 years of age. Shorter-term changes have been described during the peripubertal period when the growth of successive large follicles $(8-12 \mathrm{~mm}$ in diameter) was detected in heifers $(n=6)$ ultrasonically scanned for 23 days just before their first ovulation (cited in Roche and Boland, 1991). The composition of ovarian follicular dynamics, on a day-to-day basis, in prepubertal heifers has apparently not been investigated.

Reports on the long-term changes in circulating concentrations of gonadotrophins in heifers from birth to puberty are conflicting (Kinder et al., 1987; Moran et al., 1989). From birth to 12 months of age, two increases in LH have been reported; an early rise occurs between 12 and 20 weeks of age (Schams 
et al., 1981; Evans et al., 1992), followed by a decline and subsequent gradual rise coinciding with puberty (first ovulation) at 36-52 weeks of age (Schams et al., 1981; Day et al., 1984; Dodson et al, 1988; Evans et al., 1992). An early rise in plasma concentrations of FSH coincident with that of LH has been reported by Schams et al. (1981) and Evans et al. (1992), but the pattern of changes in FSH associated with sexual maturation is less clear. No references were found regarding temporal changes in gonadotrophins associated with ovarian follicular dynamics in prepubertal heifers.

A wave-like pattern of follicular growth has been unequivocally documented in postpubertal cattle using transrectal ultrasonic imaging (Pierson and Ginther, 1987; Savio et al., 1988; Sirois and Fortune, 1988; Knopf et al., 1989), and changes in concentrations of FSH in plasma have recently been associated with this pattern (Adams et al., 1992a). A wave of follicular growth in cattle involves the synchronous development of a group of follicles - a dominant follicle and several subordinates. Successive anovulatory follicular waves emerge until luteal regression, at which time the extant dominant follicle becomes ovulatory. Most oestrous cycles are composed of two or three follicular waves; wave emergence occurs on days 0 (day of ovulation) and 10 for two-wave cycles and on days 0,9 and 16 for three-wave cycles (Ginther et al., 1989a). The development of dominant and subordinate follicles of a wave comprises distinct growing, static and regressing phases (Ginther et al., 1989b). The dominant follicle has been shown to suppress the growth of its subordinates and to suppress the emergence of the next wave (Kastelic et al., 1990; Ko et al., 1991). The suppressive effects of the dominant follicle were associated with the suppression of circulating concentrations of FSH (Adams et al., 1992a). A surge in concentrations of plasma FSH before the emergence of each wave in two-wave and threewave oestrous cycles was involved in eliciting wave emergence (Adams et al., 1992a) and in the selection of the dominant follicle (Adams et al., 1993).

The purpose of the present study was to document the suitability of the transrectal ultrasound technique for imaging the ovaries of prepubertal heifers and to test the hypothesis that ovarian follicular development occurs in waves in prepubertal heifers. In addition, circulating concentrations of FSH and $\mathrm{LH}$ were characterized in relation to follicle development.

\section{Materials and Methods}

\section{Animals and ultrasound procedure}

Eleven age-matched ( 36 weeks of age \pm 4 days), spring-born, Hereford heifers weighing $275 \pm 14 \mathrm{~kg}$ were examined daily for 18 days by transrectal ultrasonography during December. From previous work (Evans et al., 1992), it was estimated that heifers used in the present study were 20 weeks (approximately 5 months) from puberty, defined herein as the day of first ovulation. Four weeks before the observational period, a preliminary examination was conducted on the heifers (32 weeks of age) in an initial attempt to ultrasonically image the ovaries. The small size of the heifers precluded intrarectal placement of the gloved hand; a probe extension was, therefore, prepared, as described by Adams et al. (1991), to provide the operator external leverage with which to manipulate the intrarectally placed transducer. A semirigid length of nasogastric tubing (length $40 \mathrm{~cm}$; inside diameter $1.3 \mathrm{~cm}$; outside diameter $2 \mathrm{~cm}$ ) was cut along its length and placed around the transducer cord and taped in place just behind the transducer head. The heifers were required to step up onto a platform approximately $28 \mathrm{~cm}$ high in the chute to facilitate transrectal examination. Examinations were done by a single operator using a B-mode scanner equipped with a $7.5 \mathrm{MHz}$, linear-array transducer (Aloka SSD-500, Overseas Monitor Corp. Ltd., Richmond, BC). An observational period of 18 days was arbitrarily chosen as a period that would be expected to exceed an interwave interval in sexually mature heifers and encompass the entire growing and regressing phases of a dominant follicle (Ginther et al., 1989a). Ovarian follicles $\geqslant 4 \mathrm{~mm}$ in diameter were sequentially identified and measured, as previously described for sexually mature heifers (Knopf et al., 1989), and all follicles (whether or not individually identified) $\geqslant 4 \mathrm{~mm}$ in diameter were counted.

The total number of follicles ( $\geqslant 4 \mathrm{~mm}$ in diameter) detected in both ovaries for each day was tabulated in relation to the diameter of the follicle destined to become the largest, to determine whether follicular development occurred in waves. The numbers of follicles were normalized to the day that the largest follicle was first identified, retrospectively, at a diameter of $4-5 \mathrm{~mm}$. The number of follicles included those that were individually identified (two to four follicles on each day) and those that were not individually identified. If the number of follicles increased at apparently regular intervals, the follicular pattern was defined as wave-like. A negative correlation between the number of follicles and the diameter of the largest follicle (pair-wise correlation) was taken as further indication of the presence of follicular waves. That is, emergence of a group of small follicles and subsequent growth of one follicle while the others regressed would be characteristic of a wave as described in sexually mature heifers (Ginther et al., 1989a).

The above approach indicated that follicular growth was wave-like in these prepubertal heifers; a dominant follicle of a wave was, therefore, defined as the follicle that exceeded the diameter of all other follicles in the wave and a subordinate follicle was defined as the follicle that appeared to originate from the same follicular pool as the dominant follicle (Ginther et al., 1989b). The time of selection of the dominant follicle from its subordinate was defined as the day on which the diameter of the dominant follicle exceeded that of the largest subordinate by $\geqslant 2 \mathrm{~mm}$ (Adams et al., 1993). First and second subordinates were designated on the basis of the largest diameter attained. The first day of detection of the dominant follicle, retrospectively identified at a diameter of 4 or $5 \mathrm{~mm}$, was defined as the day of wave emergence. The follicular waves were designated as the first, second and third waves detected during the observational period. Only the second wave was observed in its entirety; however, portions of the first and third waves were detected in all II heifers.

\section{Collection of blood samples and radioimmunoassays}

A blood sample was collected from the jugular vein once a day for measurement of concentrations of $\mathrm{LH}$ and $\mathrm{FSH}$ in serum. Samples were allowed to clot for 18-24 h; the clots 
were removed and the sample was centrifuged at $1500 \mathrm{~g}$ for $15 \mathrm{~min}$. The serum was poured off and stored at $-20^{\circ} \mathrm{C}$ until analysis. Concentrations of LH and FSH in serum were measured by validated radioimmunoassay (Rawlings et al., 1984; Evans ef al., 1992). LH concentrations were expressed in terms of NIDDK-bLH4. The range of the standard curve was from $0.06 \mathrm{ng} \mathrm{ml}^{-1}$ to $8.0 \mathrm{ng} \mathrm{ml}^{-1}$. The minimum detectable level (lowest concentration of unlabelled LH capable of displacing iodinated $\mathrm{LH}$ from the first antibody; $P<0.05$ by $t$ test) was $0.1 \mathrm{ng} \mathrm{ml} \mathrm{m}^{-1}$. Intra- and interassay coefficients of variation were both $7 \%$, at a mean serum concentration of $0.7 \mathrm{ng} \mathrm{ml}^{-1}$, and $10 \%$ and $11 \%$, respectively, at a mean serum concentration of $3.1 \mathrm{ng} \mathrm{ml}^{-1}$. The first antibody used for the FSH assay was NIDDK-anti-oFSH-I, and concentrations of FSH were expressed in terms of USDA-bFSH-I1. The range of the standard curve was $0.13 \mathrm{ng} \mathrm{ml}^{-1}-16 \mathrm{ng} \mathrm{ml}^{-1}$, and the minimum detectable concentration was $0.2 \mathrm{ng} \mathrm{ml}^{-1}$ serum. Intraand interassay coefficients of variation were $5 \%$ and $11 \%$, respectively, at a mean serum concentration of $3.4 \mathrm{ng} \mathrm{ml}^{-1}$, and $5 \%$ and $5 \%$, respectively, at a mean serum concentration of $7.5 \mathrm{ng} \mathrm{ml}^{-1}$.

\section{Data handling and statistical analyses}

For statistical analysis and preparation of figures, follicle diameter data for the first and second waves were normalized to the day of emergence of the second wave and, for the third wave, were normalized to the day equivalent to the mean interwave interval. Data on number of follicles were similarly normalized, but included the data for the 4 days preceding the emergence of the second and third waves. Normalized data were analysed for a day effect by analysis of variance for repeated measures.

The composition of a follicular wave in prepubertal heifers was characterized by initially preparing diameter profiles of identified follicles in each wave for each individual heifer. The diameter profile of each follicle was then partitioned into growing, static and regressing phases, as described by Ginther et al. (1989b), so that comparisons could be made amongst waves and between dominant and subordinate follicles. The growing phase extended from the day of first identification to the day that the follicle appeared to cease its progressive increase in diameter. The static phase extended from the last day of the growing phase to the first day that the follicle appeared to begin a progressive decrease in diameter. The regressing phase began on the last day of the static phase. The static phase was characterized by the number of days and by mean diameter during these days. Linear growing rates and regressing rates $\left(\mathrm{mm} \mathrm{day}^{-1}\right)$ were determined separately for each follicle and the mean slopes were calculated. Differences between characteristics of the first and second waves (regressing phase), and the second and third waves (growing and static phases), were compared by paired $t$ tests. If no differences were detected, corresponding data from the first, second and third waves were combined. Similarly, follicle diameter profiles for each phase were compared amongst waves by two-way analysis of variance (day effect and wave effect) for repeated measures. If the effects of wave and the day-by-wave interaction were not significant $(P<0.05)$, the data were combined amongst waves. Data from the growing and regressing phases were characterized by regression analyses and were fit to higher order polynomial expressions; the highest order in which all coefficients contributed $(P<0.05)$ was used to best represent the data.

Hormone data were normalized to the day of emergence of the second and third waves according to the follicle data for the corresponding day, but included the data for the 5 days preceding wave emergence as described by Adams et al. (1992a). Data were analysed for a day effect by analysis of variance for repeated measures. If a significant day effect was detected, multiple comparisons were made by the method of least significant difference and characteristic changes were compared between the second and third waves by paired $t$ tests and two-way analysis of variance for repeated measures (day effect and wave effect). A significant rise and fall in mean concentration of gonadotrophin in serum was defined as a surge (Adams et al., 1992a). The peak in the surge was defined as the day of maximum concentration within 5 days of emergence of a wave. On an individual-animal basis, an initial increase leading to a peak was defined as a value $\geqslant 2 \mathrm{SD}$ of the mean nadir, and the initial decrease was defined as a value $\geqslant 2 \mathrm{SD}$ below the mean maximum. If no differences were detected between waves, the data were combined and regression lines that best fit the data corresponding to the increase and the decrease, respectively, were constructed to display the characteristics of the surge.

\section{Results}

\section{Ultrasonography and follicle dynamics}

The ultrasound probe extension provided a method for imaging the ovaries during examinations in which intrarectal placement of a gloved hand could not be accomplished. During the preliminary examinations 4 weeks before the observational period (i.e. 32 weeks of age), ultrasound images of both ovaries were obtained in eight of 11 heifers using the probe extension, and follicles ranging in diameter from $3 \mathrm{~mm}$ to $11 \mathrm{~mm}$ were detected. Intrarectal placement of the operator's gloved hand (glove size $7 \frac{1}{2}$ ) was achieved in only three heifers. However, during the period of observation (i.e. for 18 days starting at 36 weeks of age), intrarectal placement of the operator's hand and transducer was achieved in all of the heifers; the probe extension was, therefore, not used. Although they had not previously been examined, the heifers soon became accustomed to the chute and examination procedure. Daily data collection was maintained without complication in all 11 heifers throughout the period of observation.

Ovulation was not detected ultrasonically in any heifer during the period of observation. The number of follicles $\geqslant 4 \mathrm{~mm}$ in diameter detected per heifer per day increased $(P<0.02)$ in inverse proportion $(r=-0.3, P<0.03)$ to the diameter of the follicle retrospectively identified as the follicle destined to become the largest (Fig. 1). These results were taken as an indication of a wave-like pattern of follicular development and, hereafter, the largest follicles are referred to as the dominant follicle of the first, second or third waves detected during the period of observation (Fig. 1). Successive minima in the number of follicles detected per heifer per day 

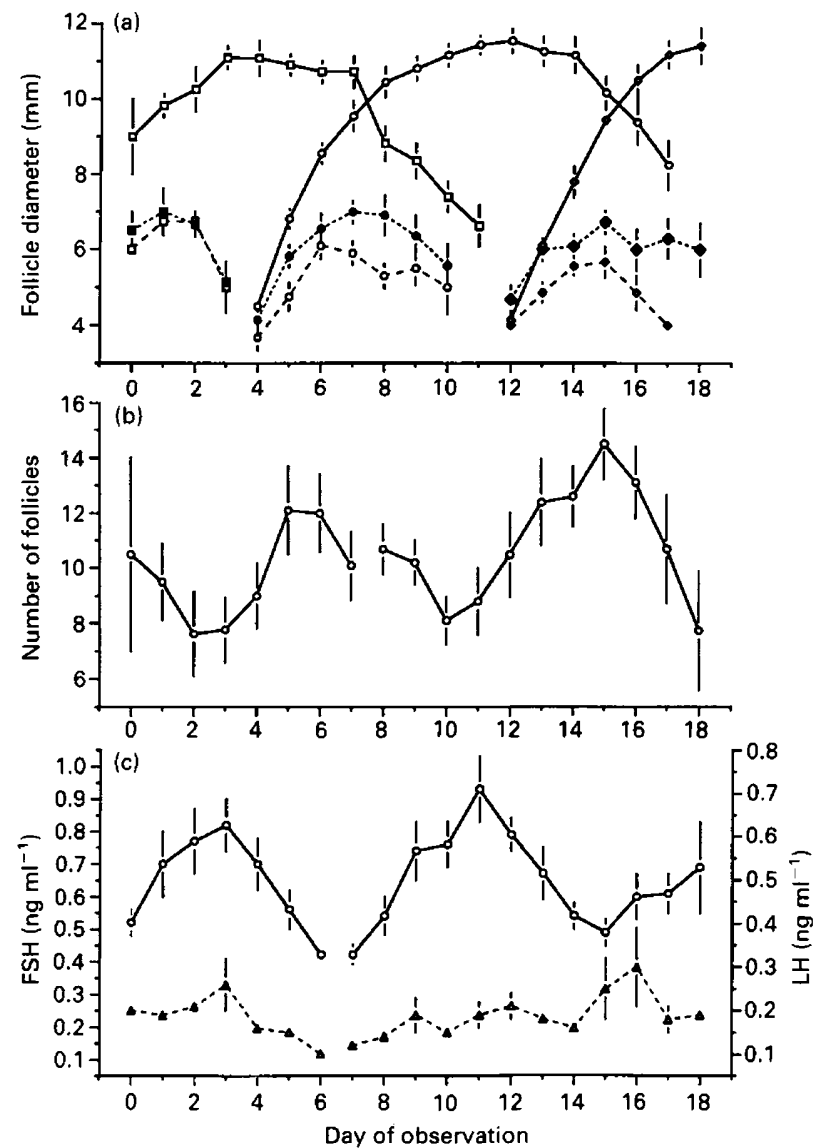

Fig. 1. (a) Diameter profiles (mean \pm SEM) of the dominant $(-$ ) and largest two subordinate (-- ) follicles of successive anovulatory waves in 36 -week-old prepubertal heifers $(n=I 1)$. (b) The number (mean \pm SEM) of follicles ( $\geqslant 4 \mathrm{~mm}$ in diameter) detected per heifer per day (day effect, $P<0.02$ ), and (c) concentrations (mean \pm SEM) of FSH ( $\longrightarrow$; day effect, $P<0.0001)$ and LH $(---$; day effect, not significant) in serum normalized to the day of emergence of the second and third follicular waves.

occurred $0.8 \pm 0.3$ days before $(5.9 \pm 1.1$ follicles) and $6.4 \pm 0.5$ days after ( $6.1 \pm 0.8$ follicles) emergence of the second wave. Successive maxima occurred $2.1 \pm 0.4$ days after (14.2 \pm 1.6 follicles) and $10.3 \pm 0.6$ days ( $16.3 \pm 0.7$ follicles) after emergence of the second wave. The period between emergence of the dominant follicles of the second and third follicular waves (interwave interval) was $8.0 \pm 0.4$ days.

Follicle data from the respective waves corresponding to the growing phase (second and third waves), static phase (first, second, and third waves) and regressing phase (first and second waves) were compared among waves and no differences were detected. Developmental characteristics of the dominant and subordinate follicles, combined among waves, are presented (Table 1, Fig. 2). Regression lines that best fit the data were used to display the characteristics of the dominant and largest subordinate follicles of a wave in the heifers (Fig. 2). The growing phase of the dominant follicle was best characterized by quadratic regression $\left(\mathrm{mm}=-0.14 \mathrm{day}^{2}+2.01\right.$ day +4.75 ; $R^{2}=0.83$ ), but the regressing phase of the dominant follicle and both the growing and regressing phases of the subordinate

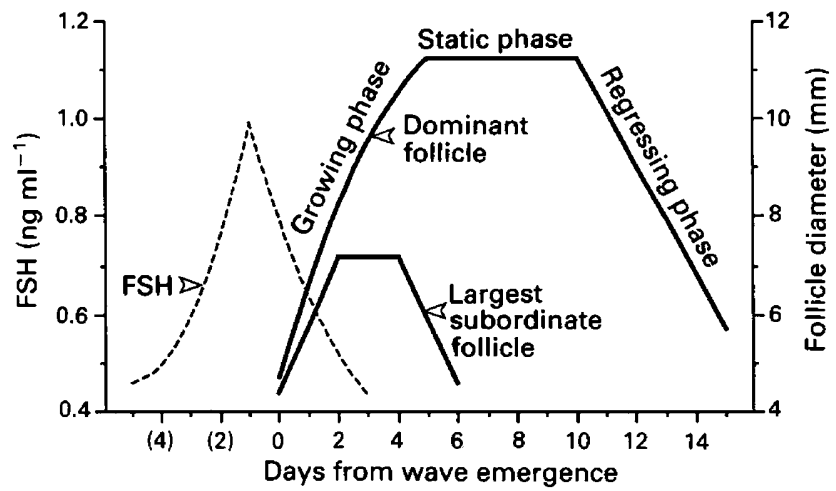

Fig. 2. Regression lines that best characterized the growing, static and regressing phases of the dominant and largest subordinate follicles $(\longrightarrow)$ of anovulatory follicular waves in 36-week-old prepubertal heifers $(n=11)$, and the increase and decrease in concentrations of FSH in serum (-- ) associated with wave emergence. No differences (follicular or hormonal) were detected in the respective phases among the successive waves of the period of observation; data for each phase were therefore combined among waves and plotted by reference to the day of wave emergence (day 0 ). The growing phase of the dominant follicle was best characterized by a quadratic equation, whereas all other growing and regressing phases were best characterized by simple linear equations. Hormone data were normalized to the day of maximum concentration in the pre-wave FSH surge; the increase and decrease comprising the surge were best characterized by quadratic equations.

follicle were best characterized by simple linear regression (Table 1). The mean diameter during the static phase was $11.2 \pm 0.2 \mathrm{~mm}$ for the dominant follicle and $7.1 \pm 0.3 \mathrm{~mm}$ for the largest subordinate follicle.

\section{Gonadotrophins}

Periodic increases in serum concentrations of FSH (day effect, $P<0.0001$ ), but not LH (day effect, not significant), were detected in data normalized in relation to follicular wave emergence (Fig. 1). Temporal relationships between surges in circulating FSH and follicular dynamics are presented (Table 2). Peak concentrations of FSH in serum preceding the second and third waves were not different $\left(1.0 \pm 0.05 \mathrm{ng} \mathrm{ml}^{-1}\right)$, nor were successive nadirs $\left(0.4 \pm 0.02 \mathrm{ng} \mathrm{ml}{ }^{-1}\right)$. A pre-wave surge (increase of $\geqslant 2 \mathrm{SD}$ above the mean nadir) was detected before the emergence of the second and third follicular waves in ten of the 11 heifers; only one surge was detected in the remaining heifer. Surge concentrations exceeded $3 \mathrm{SD}\left(0.2 \mathrm{ng} \mathrm{ml}^{-1}\right)$ of the mean nadir $\left(0.4 \mathrm{ng} \mathrm{ml}^{-1}\right)$ for an average of 3 days (range, $2-5$ days). The interval between successive maxima $(8.2 \pm 0.3$ days) or successive minima (7.8 \pm 0.4 days) in serum FSH concentration was not different from the interval between successive maxima in the number of follicles detected per heifer per day $(8.1 \pm 0.5$ days), or the interwave interval $(8.0 \pm 0.4$ days). Data representing the surges in serum concentrations of FSH preceding the second and third follicular waves were compared and no differences were detected; the data were, therefore, combined. Data from individual heifers were normalized about the maximum value of the FSH surge that occurred, 
Table 1. Characteristics of dominant and subordinate follicles of a follicular wave in 36-week-old prepubertal heifers

\begin{tabular}{|c|c|c|c|}
\hline Characteristic & Dominant follicle & First subordinate follicle & Second subordinate follicle \\
\hline Diameter at first detection (mm) & $4.6 \pm 0.2(22)^{\mathrm{a}}$ & $4.4 \pm 0.4(22)^{\mathrm{a}}$ & $4.2 \pm 0.2(20)^{\mathrm{a}}$ \\
\hline Maximum diameter (mm) & $12.0 \pm 0.3(19)^{\mathrm{a}}$ & $7.6 \pm 0.3(22)^{b}$ & $6.5 \pm 0.2(20)^{c}$ \\
\hline Growing phase (days) & $4.7 \pm 0.3(22)^{\mathrm{a}}$ & $2.2 \pm 0.2(22)^{b}$ & $1.6 \pm 0.1(20)^{c}$ \\
\hline Linear growth rate $\left(\mathrm{mm}^{-1 a y}{ }^{-1}\right)$ & $1.6 \pm 0.1(22)^{\mathrm{a}}$ & $1.4 \pm 0.1(22)^{\mathrm{a}}$ & $1.4 \pm 0.1(20)^{\mathrm{a}}$ \\
\hline Static phase (days) & $5.1 \pm 0.3(19)^{\mathrm{a}}$ & $1.8 \pm 0.2(22)^{\mathrm{b}}$ & $1.6 \pm 0.3(20)^{\mathrm{b}}$ \\
\hline Linear regressing rate $\left(\mathrm{mm}\right.$ day $\left.^{-1}\right)$ & $-1.1 \pm 0.1(22)^{a}$ & $-1.3 \pm 0.1(22)^{\mathrm{a}}$ & $-1.2 \pm 0.1(20)^{\mathrm{a}}$ \\
\hline
\end{tabular}

Values are means \pm SEM.

No differences were detected among the first, second and third waves; data were therefore combined. The number of observations is in parentheses.

${ }^{a b c}$ Within each row, values with no common superscript are significantly different $(P<0.05)$

on average, 1 day before wave emergence (Table 2). Both components of the FSH surge (increase and decrease) were best characterized by quadratic regression (increase, $\mathrm{FSH}=0.03$ day $^{2}+0.26$ day $+0.99 ; R^{2}=0.6$, and decrease, $\mathrm{FSH}=0.02$ day $^{2}-0.22$ day $\left.+1.0 ; R^{2}=0.67\right)$ (Fig. 2).

\section{Discussion}

The technique of monitoring the development of individually identified ovarian follicles described for postpubertal heifers (Knopf et al., 1989) was used in the study reported here and enabled the characterization of follicle dynamics in 36-weekold, prepubertal heifers. As part of a separate study, the mean age at puberty in these heifers (defined as the day of first ovulation) was determined as $56 \pm 0.4$ weeks. The heifers were therefore $20 \pm 0.4$ weeks (approximately 5 months) from puberty at the start of the period of observation. During the period of observation (at 36 weeks of age), all ultrasound examinations were accomplished by intrarectal placement of the operator's hand with the transducer. However, preliminary examinations (at 32 weeks of age) were done using a semirigid probe extension (Adams et al., 1991) which allowed the imaging of internal genitalia of heifers too small to accommodate manual transrectal examination. It was concluded that this technique offered the potential for studying ovarian function in calves at a much younger age.

The periodicity of follicular and hormonal events supported the hypothesis that follicular development occurs in waves in prepubertal heifers. In a similar way to the pattern described in postpubertal cattle, the simultaneous emergence of a group of small follicles followed by continued growth of one (dominant) and regression of the others (subordinates) was characteristic of follicular development detected in the prepubertal heifers studied here. The 8-day interval between maxima and minima in number of follicles and serum FSH, and between the emergence of successive dominant follicles was consistent with a wave-like pattern of follicular development.

Temporal relationships between the dominant and subordinate follicles within and between waves in the present study indicated that the influence of the dominant follicle described for postpubertal heifers was present in the prepubertal heifers.
The period from wave emergence to the divergence in the growth profiles of the dominant and first subordinate follicle (manifest selection) was remarkably similar in the prepubertal versus postpubertal heifers $(2.5 \pm 0.3$ versus $2.5 \pm 0.4$ days; Adams et al., 1993), as was the period from wave emergence to the onset of regression of the dominant follicle of the previous wave $(3.3 \pm 0.3$ versus $3.5 \pm 0.4$ days; Ginther et al., 1989a). The results obtained were consistent with the concept that the dominant follicle suppresses its subordinates and the emergence of the next follicular wave (Kastelic et al., 1990; Ko et al., 1991).

Follicular waves in the prepubertal heifers studied here were qualitatively similar, but quantitatively different from that described for postpubertal heifers (Ginther et al, 1989a, b). Apparent differences in prepubertal versus postpubertal follicle dynamics (not statistically compared) were: (i) all follicular waves were anovulatory in prepubertal heifers, (ii) the growing phase of the dominant and first subordinate follicles of anovulatory waves appeared shorter $(4.7 \pm 0.3$ versus $6.1 \pm 0.3$ days, $2.2 \pm 0.2$ versus $2.4 \pm 0.2$ days, respectively), (iii) the mean diameter of the dominant and first subordinate follicles during the static phase appeared less (11.2 \pm 0.2 versus $15.8 \pm 0.5 \mathrm{~mm}$, and $7.1 \pm 0.3$ versus $8.2 \pm 0.4 \mathrm{~mm}$, respectively), (iv) the static phase of the dominant and first subordinate follicles appeared shorter $(5.1 \pm 0.3$ versus $5.8 \pm 0.5$, and $1.8 \pm 0.2$ versus $2.1 \pm 0.3$ days, respectively), and (v) the interwave interval appeared shorter $(8.0 \pm 0.4$ versus $9.7 \pm 0.2$ days). The quantitative differences are even more profound if the effects of low circulating concentrations of progesterone are taken into consideration. Recent results indicated that progesterone suppresses follicle growth (Adams et al., 1992b); low circulating concentrations of progesterone in prepubertal heifers (Evans $e t$ al., 1992) would therefore be expected to prolong follicle growth. However, compared with anovulatory wave dynamics of postpubertal heifers in which low concentrations of serum progesterone were maintained $\left(\leqslant 2 \mathrm{ng} \mathrm{ml}^{-1}\right.$; Adams et al., $1992 \mathrm{~b})$, the growing phase of the follicle was shorter $(4.7 \pm 0.3$ versus $10.8 \pm 1.5$ days) and the maximum diameter was markedly smaller ( $12.0 \pm 0.3$ versus $20.8 \pm 1.4 \mathrm{~mm}$, respectively) in the prepubertal heifers.

Perhaps the immature hypothalamo-pituitary axis in prepubertal heifers cannot produce the concentrations of $\mathrm{LH}$ found in 
Table 2. Temporal relationships between surges in serum concentrations of FSH and the emergence, selection, and regression of the dominant follicle of follicular waves in 36-week-old prepubertal heifers

\begin{tabular}{|c|c|c|c|}
\hline \multirow[b]{2}{*}{ Characteristic } & \multicolumn{2}{|c|}{ Days from emergence of } & \multirow[b]{2}{*}{ Average $^{\mathbf{a}}$} \\
\hline & Second wave & Third wave & \\
\hline Initial increase in $\mathrm{FSH}^{*}$ & $-1.8 \pm 0.3$ & $-2.6 \pm 0.2(11)$ & $-2.3 \pm 0.2(17)$ \\
\hline Maximum FSH & $-0.9 \pm 0.3$ & $-1.0 \pm 0.3(11)$ & $-1.0 \pm 0.2(18)$ \\
\hline Initial decrease in $\mathrm{FSH}^{*}$ & $1.0 \pm 0.3$ & $1.3 \pm 0.3(11)$ & $1.2 \pm 0.2(19)$ \\
\hline Minimum FSH & $2.9 \pm 0.3(11)$ & $3.1 \pm 0.2(11)$ & $3.0 \pm 0.2(22)$ \\
\hline Follicle selectiont & $2.7 \pm 0.5(11)$ & $2.4 \pm 0.4(11)$ & $2.5 \pm 0.3(22)$ \\
\hline Regression of previous dominant follicle & $3.5 \pm 0.3(11)$ & $3.1 \pm 0.5(11)$ & $3.3 \pm 0.3(22)$ \\
\hline
\end{tabular}

\footnotetext{
Values are means \pm SEM.

The waves were the second and third detected during the observational period. The number of observations is in parentheses.

*Increase of $\geqslant 2 \mathrm{SD}$ above the mean nadir, and decrease of $\geqslant 2$ SD below the mean maximum.

†First day the diameter of the dominant follicle exceeded that of the first subordinate follicle by $\geqslant 2 \mathrm{~mm}$.

${ }^{a}$ No significant effect of wave was detected for any endpoint, and values for all endpoints were significantly different $(P<0.03)$ from zero (day of wave emergence).
}

mature animals (basal concentrations or pulse frequency), despite low circulating concentrations of progesterone. The hypothesis that increased LH pulse frequency, as a result of low circulating concentrations of progesterone, is responsible for promoting continued growth and prolonged maintenance of the dominant follicle (Adams et al., 1992b) was supported by a study by Stock and Fortune (1993), in which heifers that received only one intravaginal progesterone-releasing device had a higher LH pulse frequency and prolonged dominant follicle growth compared with heifers that received two devices. Although LH pulse frequency was not assessed in the present study, failure of the dominant follicles to attain a greater diameter profile in the prepubertal heifers may be attributable to relatively less LH support compared with that in sexually mature cattle.

Linear growth and regression rates of the dominant follicle ( $1.6 \pm 0.1$ versus $1.8 \pm 0.1 \mathrm{~mm} \mathrm{day}^{-1}$, and $-1.1 \pm 0.1$ versus $-1.0 \pm 0.1 \mathrm{~mm} \mathrm{day}^{-1}$, respectively) and first subordinate follicle ( $1.4 \pm 0.1$ versus $1.3 \pm 0.1 \mathrm{~mm}^{-1}$ day $^{-1}$, and $-1.3 \pm 0.1$ versus $-1.0 \pm 0.1 \mathrm{~mm}^{-1}{ }^{-1}$, respectively) appeared similar in prepubertal versus postpubertal heifers. In postpubertal heifers (Ginther et al., 1989b), the growing phase of the dominant anovulatory follicle was depicted by simple linear regression, but that of the dominant ovulatory follicle best fit a quadratic curve. The growing phase of the dominant follicle in prepubertal heifers studied here (anovulatory) best fit a quadratic curve.

Changes in concentrations of FSH in serum relative to follicular wave dynamics were remarkably similar in the present study to those reported by Adams ef al., (1992a), despite the fact that the studies were conducted in different laboratories, using different FSH assays and heifers of different ages and breeds. In postpubertal heifers (Adams et al., 1992a), it was concluded that surges in FSH in serum were responsible for eliciting wave emergence. Temporal associations detected in the prepubertal heifers studied here were consistent with the concept of a functional relationship between FSH surges and wave emergence. In the present and previous studies, surges in FSH spanning approximately 3 days reached a maximum, on average, 1 day before the emergence of each follicular wave. In addition, the temporal relationship between the post-surge decline in FSH and the manifestation of selection observed in the study reported here is consistent with reports in post-pubertal heifers (Adams et al., 1992a, 1993) in which decreasing FSH concentrations in plasma were implicated in the mechanism of dominant follicle selection. Compared with postpubertal heifers in which the same assay was used to measure gonadotrophins (Bo et al., 1993), the range in mean daily concentrations of FSH $\left(0.3-0.7 \mathrm{ng} \mathrm{ml}^{-1}\right)$ and $\mathrm{LH}\left(0.2-0.4 \mathrm{ng} \mathrm{ml}^{-1}\right)$ were similar to those detected in prepubertal heifers in the study reported here.

In conclusion, follicular development occurred in waves in 36-week-old prepubertal heifers. Wave emergence and dominant follicle selection, respectively, were temporally associated with a pre-wave surge in plasma FSH and the post-surge decline. In a similar way to that described for sexually mature heifers, the well-ordered phenomena of wave emergence, follicle selection and follicle regression were present in 36-week-old prepubertal heifers. Because follicle diameter profiles appeared smaller than those of sexually mature heifers but similar in pattern, results provided a rationale for the hypothesis that maturation in the dynamics of ovarian follicle development and its control is primarily a quantitative process rather than a qualitative process, with the obvious exception of ovulation. Direct comparison of ovarian function in heifers at different stages from birth to puberty will be needed to test the hypothesis, and may be feasible using the ultrasound technique described here. The issues of when the well-ordered wave-like pattern of follicular growth is established during prepubertal life and what its function might be in sexual maturation remain to be addressed. Perhaps prepubertal cyclic exposure to steroidal and nonsteroidal follicular products is essential for maturation of the hypothalamo-pituitary-ovarian axis and the culmination of puberty. In addition, prepubertal follicular dynamics may hold predictive information about postpubertal reproductive function (performance). 
This research was supported by the Western College of Veterinary Medicine, University of Saskatchewan and the Natural Sciences and Engineering Research Council of Canada. The authors thank S. Cook for assistance with radioimmunoassays, and B. Kerr and the Goodale Research Farm staff for supplying and maintaining the heifers.

\section{References}

Adams GP, Plotka ED, Asa CS and Ginther OJ (1991) Feasibility of characterizing reproductive events in large nondomestic species by transrectal ultrasonic imaging Zoo Biology 10 247-259

Adams GP, Matteri RL, Kastelic JP, Ko JCH and Ginther OJ (1992a) Association between surges of follicle-stimulating hormone and the emergence of follicular waves in heifers Journal of Reproduction and Fertility 94 177-188

Adams GP, Matteri RL and Ginther OJ (1992b) Effect of progesterone on ovarian follicles, emergence of follicular waves and circulating folliclestimulating hormone in heifers Journal of Reproduction and Fertility 95 $627-640$

Adams GP, Kot K, Smith CA and Ginther OJ (1993) Selection of a dominant follicle and suppression of follicular growth in heifers Animal Reproduction Science $30259-271$

Bo GA, Adams GP, Nasser LE, Pierson RA and Mapletoft RJ (1993) Effect of estradiol valerate on ovarian follicles, emergence of follicular waves, and circulating gonadotropins in heifers Theriogenology $40225-239$

Day ML, Imakawa K, Garcia-Winder M, Zalesky DD, Schanbacher CD, Kittok RJ and Kinder JE (1984) Endocrine mechanisms of puberty in heifers: estradiol negative feed-back regulation of luteinizing hormone secretion Biology of Reproduction 31 332-341

Desjardins C and Hafs HD (1969) Maturation of bovine female genitalia from birth through puberty Joumal of Animal Science 28 502-507

Dodson SE, McLeod BJ, Haresign W, Peters AR and Lamming GE (1988) Endocrine changes from birth to puberty in the heifer Joumal of Reproduction and Fertility 82 527-538

Erickson BH (1966) Development and senescence of the postnatal bovine ovary Journal of Animal Science 25 800-805

Evans ACO, Currie WD and Rawlings NC (1992) Effects of naloxone on circulating gonadotrophin concentrations on prepubertal heifers Journal of Reproduction and Fertility 96 847-855
Ginther OJ, Knopf L and Kastelic JP (1989a) Temporal associations among ovarian events in cattle during oestrous cycles with two and three follicular waves Journal of Reproduction and Fertility 87 223-230

Ginther OJ, Kastelic JP and Knopf L (1989b) Composition and characteristics of follicular waves during the bovine oestrous cycle Animal Reproduction Science $20 \quad 187-200$

Kastelic JP, Ko JCH and Ginther OJ (1990) Suppression of dominant and subordinate ovarian follicles by a proteinaceous fraction of follicular fluid in heifers Theriogenology 34 499-509

Kinder JE, Day ML and Kittock RJ (1987) Endocrine regulation of puberty in cows and ewes Joumal of Reproduction and Fertility Supplement 34 167-189

Knopf L, Kastelic JP, Schallenberger E and Ginther OJ (1989) Ovarian follicular dynamics in heifers: test of two-wave hypothesis by ultrasonically monitoring individual follicles Domestic Animal Endocrinology 6 111-119

Ko JCH, Kastelic JP, Del Campo MR and Ginther OJ (1991) Effects of a dominant follicle on ovarian follicular dynamics during the oestrous cycle in heifers Journal of Reproduction and Fertility 91 511-519

Moran C, Quirke JF and Roche JF (1989) Puberty in heifers: a review Animal Reproduction Science 18 167-182

Pierson RA and Ginther OJ (1987) Follicular populations during the estrous cycle: influence of day Animal Reproduction Science 124 165-176

Rawlings NC, Jeffcoate IA and Reiger DL (1984) The influence of oestradiol-17 $\beta$ and progesterone on peripheral serum concentrations of luteinizing hormone and follicle-stimulating hormone in the ovariectomized ewe Theriogenology 22 473-488

Roch JF and Boland MP (1991) Turnover of dominant follicles in cattle of different reproductive states Theriogenology 35 81-90

Savio JD, Keenan L, Boland MP and Roche JF (1988) Pattern of growth of dominant follicles during the oestrous cycle of heifers Journal of Reproduction and Fertility 83 663-671

Schams D, Schallenberger E, Gombe S and Karg H (1981) Endocrine patterns associated with puberty in male and female cattle Joumal of Reproduction and Fertility Supplement 30 103-110

Sirois J and Fortune JE (1988) Ovarian follicular dynamics during the oestrous cycle in heifers monitored by real-time ultrasonography Biology of Reproduction 39 308-317

Stock AE and Fortune JE (1993) Ovarian follicular dominance in cattle: relationship between prolonged growth of the ovulatory follicle and endocrine parameters Endocrinology 132 1108-1114 